\title{
APPENDIX M
}

\section{INTERVENTIONS FOR FORMERLY INCARCERATED INDIVIDUALS}

\section{THE ROAD NOT TAKEN: EXPLORING CAREER JOURNEY AS LIFE STORY}

\section{Karen J. Haas}

This intervention is beneficial to adolescents or adults who are in the process of exploring their identity, seeking purpose in life, and looking for a career that is meaningful to them as individuals. This intervention can be especially powerful for those clients who view themselves as unsuccessful or as having no particular talents or skills because they define themselves by their past life stories. The theoretical orientation centers on the narrative or storied approach to career counseling. Narrative counseling is used here as a means of helping the client to discover how life stories define him or her and how to move past these stories to reauthor a more powerful and positive narrative (Nafziger \& DeKruyf, 2013; Rehfuss, 2009; Thomas $\mathcal{E}$ Gibbons, 2009). Through a series of activities, the counselor and client work together to co-construct or uncover and explore the client's life story and then to deconstruct or explore unproductive themes and patterns in the individual's life strategies. The counselor follows this interactive exploration of the client's story with an exercise to determine client values. In the final phase, the counselor helps the client to reauthor and construct a new, more productive story built on dignity and competence. The session activities conclude with the counselor and client teaming to develop steps toward achieving the client's career goals. With modification, this intervention can also be delivered in a small group format.

Materials Required: Sheets of paper, colored pencils or markers, pens/pencils, Exercise 1: Who Am I? Identity Mind Map Activity Sheet, Exercise 2: Lifeline Activity Sheet, Exercise 3: Defining Values Activity Sheet, Exercise 4: Reimagining Future Career Story Activity Sheet.

Preparation Needed: Copies of activity sheets. 


\section{Activity Directions:}

1. Ask clients how they would describe themselves to someone who did not know them. In preparation for this activity, give them Exercise 1, the Who Am I? Identity Mind Map. During this co-construction phase, you are helping clients to uncover and explore their life/career narrative.

2. Next, give clients Exercise 2, the Lifeline Activity Sheet, along with some newsprint and colored pencils or markers, and ask them to chart a lifeline of defining and memorable episodes in their life/career story, including the high points and times of distress and hardship. After allowing sufficient time to complete the lifeline, ask clients to describe the impact, both positive and negative, of these events on their lives. Your role, as counselor, is to listen without criticism in order to develop an understanding of the experiences, events, and people that clients thought were important. During this storytelling time, ask both facilitating and clarifying questions, such as: What does that experience say about what's important to you? or What is the significance of that time in your life? or What have you learned from that experience? (Brott, 2011).

3. Moving into the deconstruction or unpacking phase of the session, help clients to identify patterns or themes in their narratives and unproductive rules or strategies they chose to live by that may have been influenced by the events or people in their lives. In addition, explore with clients missed opportunities, the road not taken, that may have occurred due to life events, such as the sudden death of a parent during childhood or adolescence, divorce, an unexpected move, or severe illness. Point out to clients developmental demands on decision making, and help them to understand that decisions and events in the past do not dictate decisions and choices in the future. Encourage clients that they are active agents in their own life/ career stories and can author new and enriched narratives to follow that road not taken.

4. Continuing with the deconstruction phase, provide clients with the Defining Values Activity, Exercise 3, to help determine the best direction toward their life/career goals. Ask clients to identify the top 10 values they hold most dear in living and working. To facilitate this activity, invite clients to identify times when they were happiest, most proud, and most fulfilled and satisfied. When they are ready, have them talk through their chosen values in rank order.

5. To help them reauthor their life/career story in more powerful and positive directions, work together with clients to consider different perspectives on life strategies that incorporate their personal life/work values and strengths.

6. Then team with clients to create a goal map together, Reimagining Future Career Story, Exercise 4, to explore options as a way of reauthoring the future. This activity helps clients to clarify their choices, generate alternatives, and extend the story into the future. Have an obstacles category and then identify resources, bridges, and solutions to overcome these obstacles (construction process).

7. To conclude the session, guide clients to create three steps toward reaching their career goal. 


\section{EXERCISE 1: WHO AM I? IDENTITY MIND MAP ACTIVITY SHEET}

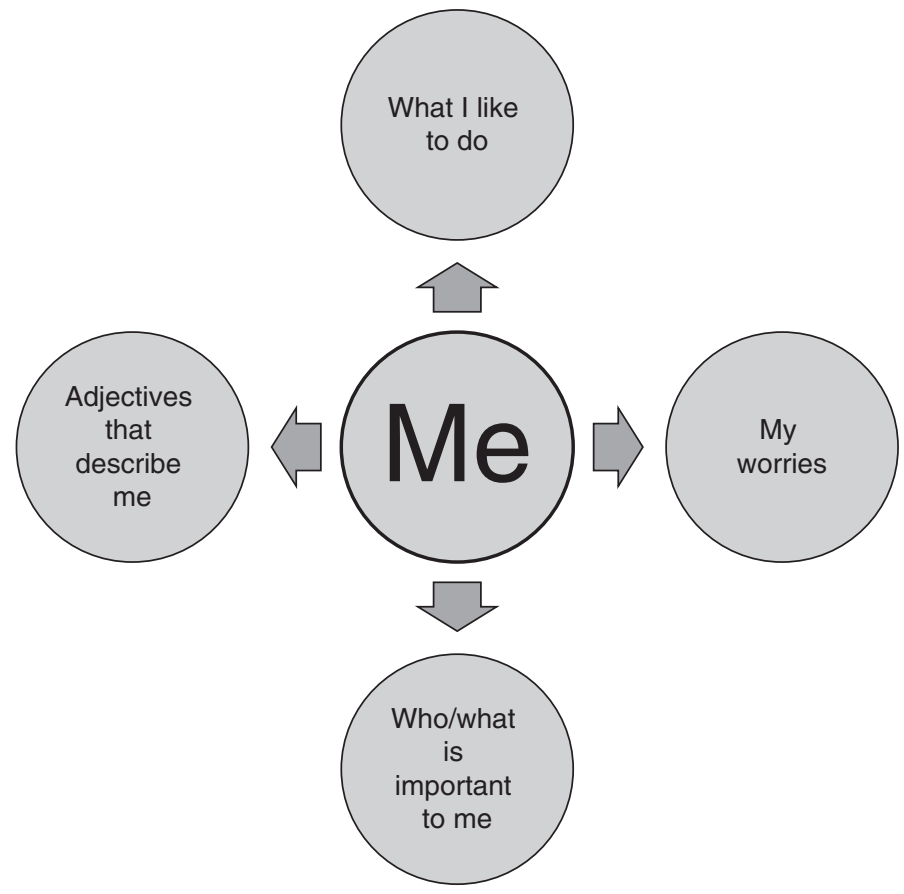

Directions: Create a Mind Map using the paper provided that depicts characteristics and qualities that you feel are important in defining who you are. You can use the previous example to get you started, and then add more circles as you complete your self-description.

\section{EXERCISE 2: LIFELINE ACTIVITY SHEET}

Directions: Chart the memorable events in your life, both positive and negative. Use the newsprint and colored pencils/markers provided.

\section{Highlights}

\begin{tabular}{lllllllll}
\hline Age & 0 & 10 & 20 & 30 & 40 & 50 & 60 \\
\hline Neutral & \\
\hline
\end{tabular}




\section{EXERCISE 3: DEFINING VALUES ACTIVITY SHEET}

Directions: This exercise is designed to help you reach a better understanding of your most significant values. From this list of values (both career and life), circle the 10 that are most important to you as guides for how to behave and/or as components of a valued way of life. Feel free to add any values of your own to this list.

\begin{tabular}{|c|c|c|}
\hline Achievement & Financial gain & Physical challenge \\
\hline Advancement & Freedom & Pleasure \\
\hline Adventure & Friendships & Power and authority \\
\hline Affection (love and caring) & Growth & Privacy \\
\hline Arts & Having a family & Public service \\
\hline Being around people who & Helping other people & Purity \\
\hline are open and honest & Helping society & Quality of what I take \\
\hline Challenging problems & Honesty & part in \\
\hline Change and variety & Independence & Quality relationships \\
\hline Close relationships & Influencing others & Recognition \\
\hline Community & Inner harmony & Religion \\
\hline Competence & Integrity & Reputation \\
\hline Competition & Intellectual status & Responsibility \\
\hline Cooperation & Involvement & Security \\
\hline Country & Job tranquility & Self-respect \\
\hline Creativity & Knowledge & Serenity \\
\hline Decisiveness & Leadership & Sophistication \\
\hline Democracy & Location & Stability \\
\hline Ecological awareness & Loyalty & Status \\
\hline Economic security & Market position & Supervising others \\
\hline Effectiveness & Meaningful work & Time freedom \\
\hline Efficiency & Merit & Truth \\
\hline Ethical practice & Money & Wealth \\
\hline Excellence & Nature & Work under pressure \\
\hline Excitement & Order (tranquility and & Work with others \\
\hline Fame & conformity) & Working alone \\
\hline Fast living & Personal development & \\
\hline
\end{tabular}




\section{EXERCISE 4: REIMAGINING FUTURE CAREER STORY ACTIVITY SHEET}

Career Goal:

Obstacles:

Resources:

Three Steps to Take Toward Reaching Goal:

1.

2.

3. 


\section{UNVEILING INSTITUTIONAL BARRIERS WHILE EMPOWERING INDIVIDUALS FOR SUCCESS}

\section{Erin N. Friedman and Katherine M. Wix}

Currently, minorities, including formerly incarcerated individuals, are facing a number of barriers in the workplace, including institutional bias, differential workplace treatment, and microaggressions. By combining the principles of cognitive behavioral therapy and the creative underpinnings of narrative therapy, clients can explore negative patterns of thinking and processing embedded stereotype threats impacting their career identities. Clients work to story edit based on new cognitive perceptions. Story-editing approaches can reduce stigma, improve personal strengths, regulate emotions, and create goals by teaching clients how to revise negative stories or tweak personal stories in beneficial ways (Cook, 2011). This intervention helps clients identify stereotypes of differential treatment they are experiencing in the workplace, discuss the effects this treatment or different expectations can have on their identity, and recognize workplace discrimination and change their own thought processes to reduce its harmful effects and empowering themselves. The objectives of this intervention include the following: empower clients in their career setting and reimagine career identity, replace harmful internalized messages with positive messages, and recognize and acknowledge the existence and impact of discrimination and stereotypes.

Materials Required: Paper, highlighter, and writing utensils.

Preparation Needed: None.

\section{Activity Directions:}

1. This activity uses story editing to address discrimination and stereotypes in addition to increasing career self-concept through reflective writing exercises. Begin the session by describing institutional bias and discrimination in the workplace. You can also discuss how these negative stereotypes or differential treatment based on an individual's identity can be internalized and lead to harmful beliefs about oneself as well as impede performance. Direct clients to write out their personal career stories, including as much detail as possible (their narrative). Clients will need to include all barriers they have encountered in the workplace or during their career endeavors. Once clients have written out their story, you and the clients work together to identify (and highlight) all negative stereotypes woven throughout the story. Provide a questionnaire on workplace discrimination to help clients identify areas of discrimination they have personally experienced, because clients may not be able to readily generate experiences of institutional or personal discrimination. Given the nature of how deep-seated many of these beliefs are, it is important that you allow clients a space to process feelings and beliefs about inadequacies that relate to career experiences. Describe the role story editing can play in both the clients' career experiences and personal life. With the clients, you will process possible solutions, identify strengths, and create new goals to reach career aspirations. 
Process Questions:

1. What did you learn about yourself through the story-editing process?

2. What barriers will you need to confront?

3. What are some possible new strategies you can implement?

4. How can you use your story edits to address moments of discrimination in your work setting?

5. In the face of discrimination, what will your role be?

Follow-Up:

1. Counselors will have clients write a letter (or series of letters) to themselves before they terminate work with one another. Counselors will then send clients this letter (or series of letters) that specifies the client strengths, accomplishments, alternative stories (generated by the clients), and any other key reminders they would like to remind themselves of the work they did with counselors. 
